\title{
Para brincar com caixas pretas: desprogramando dispositivos midiáticos
}

\section{Bárbara Héllen Menezes Fraga}

Mestra; Universidade Federal da Paraíba, João Pessoa, PB, Brasil academicobarbarafraga@gmail.com

\section{Isabella Chianca Bessa Ribeiro do Valle}

Doutora; Universidade Federal da Paraíba, João Pessoa, PB, Brasil

isabella.valle@academico.ufpb.br

\section{Resumo}

No artigo proposto, passeamos por conceitos apresentados por Vilém Flusser buscando, sobretudo, os que fazem referência à liberdade dos funcionários na era dos aparelhos, atuando por entre as brechas das programações. Tentamos entender como, deste modo, a subversão das pré-determinações dos programas com os quais nos relacionamos pode ser construída enquanto prática. A ideia proposta pelo autor é que tais transgressões se tratam de um jogo de usos criativos e expansivos das mídias, bem como formas de resistência a padrões de repetição, que visam a seus próprios interesses e configuram os programas. Propomos uma aproximação teórica das colocações de Flusser, no que chamou de filosofia da fotografia, com os conceitos de Corpo sem Órgãos, de Gilles Deleuze e Félix Guattari, e os conceitos foucaultianos de dispositivo e contradispositivo, apresentados por Giorgio Agamben. Segundo Flusser, o perigo de sermos dominados pelos aparelhos está em não os desafiarmos e em não compreendermos suas linguagens. Para o filósofo, mesmo os acasos estão inscritos no programa e, por consequência, podem, em certo momento, se realizar. Contudo, o jogo está em perceber como podemos agir em função não mais apenas das probabilidades previstas pelos programas, mas também das intenções humanas que nos permitem jogar a favor das possibilidades improváveis.

\section{Palavras-chave}

Caixa Preta. Filosofia da fotografia. Imagens Técnicas. Imaginadores. Vilém Flusser. 


\section{Introdução}

O filósofo tcheco Vilém Flusser (1920-1991), em seu $O$ universo das imagens técnicas: elogio da superficialidade (2008), publicado pela primeira vez em 1985, já nos advertia, logo no início de sua discussão, de que cada vez mais seria necessário nos preparar para os tempos que viriam. No centenário de seu nascimento, suas assertivas tornam-se cada vez mais aplicáveis à atual realidade cotidiana. Muitos dos seus apontamentos, tidos como presságios, mas já observáveis no século passado, encontram reverberações potentes nas práticas midiáticas contemporâneas, que seguem em constante processo de reconfiguração, ao encontro de muitas das reflexões do pensador em questão.

Ao pensarmos sobre a ampla incidência de processos tecnomediados na bios midiática ${ }^{1}$ digital em que estamos inseridos, atravessados por conteúdos que transitam entre imagens técnicas ${ }^{2}$ cada vez mais recorrentes, a dimensão da importância de tantos conceitos flusserianos ao pensamento no campo da Comunicação pode tornar-se locus relevante para a construção de inúmeras discussões férteis sobre os panoramas atuais. Em tal cenário, por exemplo, uma das tantas reflexões possíveis se dá a respeito das considerações de Flusser sobre os programas ${ }^{3}$, que, segundo ele (2002, p. 22), limitam as potencialidades dos aparelhos ${ }^{4}$, pois estariam previamente pré-determinados por aqueles que os produzem.

Nesse sentido, nos interessa perceber alguns desses conceitos propostos pelo filósofo, acima citados, sobretudo os que fazem referência à liberdade dos funcionários ${ }^{5}$ na era dos aparelhos. De acordo com Flusser, o conceito de programação está relacionado ao fato de que mesmo os acasos são possibilidades inseridas no programa dos aparelhos, pois, se não estivessem pré-estabelecidos enquanto virtualidades, não poderiam ser realizados. De todo modo, nosso objetivo aqui é compreender algumas possibilidades de ir além dos caminhos mais prováveis nessas programações pré-estabelecidas.

Nós, os funcionários midiáticos contemporâneos, vivemos mergulhados em sistemas de comunicação digital programados. A nossa busca pela extração máxima das

\footnotetext{
1 “A midiatização ser pensada como tecnologia de sociabilidade ou um novo bios, uma espécie de quarto âmbito existencial [...] O que já se fazia presente, por meio da mídia tradicional e do mercado, no ethos abrangente do consumo, consolida-se hoje com novas propriedades por meio da técnica digital" (SODRÉ, 2001, p.116).

2 "As imagens técnicas são represas de informação a serviço da nossa imortalidade" (FLUSSER, 2008, p.32).

3 De acordo com Flusser $(2002 ; 2008)$, os programas são sistemas que processam elementos pontuais ao acaso e que acabam por recombinar constantemente os mesmos elementos.

4 "Ferramentas que produzem signos e produtos indiretos dos textos, os aparelhos são necessariamente abstrações em terceiro grau. Extremamente complexos e sempre com um conceito por trás, eles são dificilmente decifráveis, exatamente por parecerem óbvios, como se o seu significado estivesse automaticamente dado. Eles representam os artefatos pós-industriais e hoje culminam no universo digital" (FLUSSER, 2002, p.55).

5 Denominação feita por Flusser (2002, p. 18) para referir-se às pessoas que brincam e agem em função dos aparelhos.
} 
possibilidades no uso das ferramentas presentes nesses aparelhos deságua, muitas vezes, em alterações que incidem sobre sua obviedade, os remodelam e, por vezes, até os reprogramam, os expandem, mesmo que não seja de forma intencionada. Desse modo, o tensionamento direcionado em prol de novas atuações acaba por moldar conteúdos midiáticos e os programas que os atravessam.

Ao nos referirmos a quebras de programação, estaremos relacionando-as não aos acasos não programados - o que seria impossível, segundo Flusser, mas aos acasos improváveis. Visto que, para Flusser (2002), funcionar seria permutar símbolos préestabelecidos, colocamos aqui em destaque aqueles usos que fazem os funcionários se tornarem seres brincantes, por ele denominados fotógrafos ${ }^{6}$. Assim, os fotógrafos são funcionários que buscam os usos não imediatamente previstos (mesmo que previamente programados), eles jogam com as possibilidades que ainda não foram realizadas, ou mesmo esperadas, por seus programadores ou por funcionários comuns. Nesse sentido, o intuito é perceber flusserianamente esses seres enquanto jogadores que brincam com pedaços disponíveis de informação. No entanto, para atingirmos tais rupturas, seria necessário, então, trabalharmos diretamente nas fábricas ou nas empresas que constroem e programam os aparelhos? O aparelho projetado consegue apenas produzir criações previstas, controladas pelos seus programadores?

Ao apontar que a liberdade expressa nas imagens técnicas está, de certo modo, relacionada a uma escolha programada, Vilém Flusser (2008) nos traz um ponto importante de reflexão que é a necessidade de decifrarmos, em certa medida, quais as prédeterminações que incidem sobre programas e quais delas são, de fato, colocadas de forma imperativa ao ponto de não conseguirmos agir para além das limitações por elas impostas. 0 grande desafio é perceber, por meio da observação dos usos de aparatos tecnológicos e das imagens técnicas por eles produzidas, como podemos expandir a programação das ferramentas que as compõem, em busca de suas potencialidades ${ }^{7}$, nos tornando mais do que meros apertadores de botões.

Para tratarmos do assunto, propomos uma aproximação teórica entre as colocações de Flusser (2002; 2008) e outros filósofos, a saber: os franceses Gilles Deleuze e Félix Guattari (1996) e o italiano Giorgio Agamben (2009), no intuito de constelar uma certa compreensão da não obviedade teleológica possível no uso das ferramentas que nos cercam,

\footnotetext{
6 "O fotógrafo caça, a fim de descobrir visões até então jamais percebidas. E quer descobri-las no interior do aparelho. Na realidade, o fotógrafo procura estabelecer situações jamais existentes antes. [...] Situações que estão programadas sem terem ainda sido realizadas" (FLUSSER, 2002, p.38).

7 “[...] o fotógrafo se esforça por descobrir potencialidades ignoradas. O fotógrafo manipula o aparelho, o apalpa, olha para dentro e através dele, a fim de descobrir sempre novas potencialidades" (FLUSSER, 2002, p.31-32).
} 
como veremos mais à frente. A proposta é mergulharmos nos conceitos-chave da filosofia da fotografia flusseriana, abordadas em Filosofia da Caixa Preta - Ensaios para uma futura filosofia da fotografia (2002) $)^{8}$ e em $O$ universo das imagens técnicas: elogio da superficialidade (2008), traçando associações epistemológicas entre esses conceitos e a ideia de Corpo sem Órgãos (DELEUZE; GUATTARI, 1996), formulada em diálogo com as reflexões de Antonin Artaud, bem como com os conceitos foucaultianos de dispositivo e contradispositivo, organizados, interpretados e desenvolvidos por Agamben (2009). Além disso, trazemos as considerações do brasileiro Davis Moreira Alvim (2012) acerca da última postulação teórica citada. Tal proposta aponta vetores norteadores das nossas reflexões neste texto, que são de caráter fundamentalmente teórico, mas, ao fim, se relacionam com algumas aplicações midiáticas mais concretas, as quais levantamos como possíveis exemplos.

Buscamos, por meio de tais percursos, pensar sobre algumas dinâmicas de possibilidades que um funcionário tem para atuar como fotógrafo, por entre as brechas das programações, e como, deste modo, a subversão das pré-determinações dos programas com os quais se relacionam pode ser construída enquanto prática. Nesse sentido, por mais que esse universo de possibilidades seja finito, sua delimitação se daria a partir da capacidade do fotógrafo de tornar virtualidades em atualidades.

No sentido de Pierre Lévy (2010), o virtual refere-se a algo que, embora esteja no campo do possível, não necessariamente foi materializado, atualizado. É aquilo que está no campo das potencialidades, tornando-se atual no momento em que determinada possibilidade se concretiza. Assim, nem sempre o que é possível é óbvio, esperado ou necessariamente provável, fazendo com que a prática seja configurada por meio do desafio do funcionário criativo em jogar dentro de um campo de possibilidades finito e restrito pelas programações de um aparelho, buscando brincar com aquilo que é previsto.

Se, por um lado, tratamos aqui das quebras de programação enquanto potencialidades, por outro, lembremos que o autor (FLUSSER, 2002) também deixa claro que estamos todos, mesmo os mais preparados, limitados às restrições dos programas. Há um circuito em que estão decididas as conexões possíveis, as combinações alcançáveis. De todo modo, a relação proposta (FLUSSER, 2008) é que tais "transgressões" se refiram a explorações de usos expansivos das mídias, bem como formas de resistência a padrões pré- 
estabelecidos por agentes que modulam os aparelhos, os utilizando também a partir de seus próprios interesses.

Segundo Flusser (2002), o perigo de sermos dominados pelos aparelhos pode ser gerado ao não desafiarmos seus funcionamentos internos e, assim, ao não nos apropriarmos de suas linguagens. Por mais que o filósofo aponte que mesmo os acasos pouco prováveis estão inscritos no programa e podem acabar por se realizar aleatoriamente em determinado momento, o que nos interessa aqui é perceber o jogo entre recorrências e desvios dessas pré-determinações na prática dos funcionários. Nesse sentido, permitindo-nos estar em função não apenas dos programas, mas também das intenções que nos permitem jogar ${ }^{9}$ a favor das possibilidades improváveis.

\section{A programação de dispositivos: organismos e órgãos teleológicos}

Ao ler as obras de Vilém Flusser (2002; 2008), logo deparamos com alguns conceitos apresentados por ele, tais como programa, aparelho, funcionário, entre outros tantos abordados em seus escritos, como já brevemente apontamos. Chamamos agora a atenção para duas observações feitas pelo filósofo: a de que o aparelho fotográfico serviria como uma base para entendermos os demais aparelhos futuros (filosofia da fotografia); e o conceito de programação, definido por ele para pensarmos acerca desse tipo de dispositivo (os aparelhos), pontuando que o estar programado é uma de suas principais características.

Na década de 1980, quando foram escritas as obras aqui predominantemente analisadas, estávamos nos primórdios da era digital propriamente dita, quando os primeiros computadores pessoais começavam a ser comercializados, mas a World Wide Web só viria a aparecer na década seguinte. Flusser, como visionário, baseou-se no que percebia de mais tecnologicamente elaborado na criação do que chamou de imagens técnicas: a câmera fotográfica, para construir sua teoria dos aparelhos, que hoje encontra aplicabilidade em todo universo informático e comunicacional. Assim, a filosofia da fotografia flusseriana traz os fotógrafos como representantes do que podemos definir como os imaginadores digitais. Dito isso, para pensarmos sobre as programações dos aparelhos como um todo, decidimos traçar possíveis encontros entre os apontamentos de Vilém Flusser, em seus estudos midiáticos, e algumas assertivas de outros filósofos. Flusser, Gilles Deleuze e Félix Guattari e Michel Foucault, apesar de contemporâneos, não partilharam dos mesmos termos ou se

9 As palavras jogar e brincar são utilizadas neste artigo de forma sinônima, tendo em vista que Vilém Flusser, nas obras aqui em questão, também as utilizou de modo alternado e/ou com sentido semelhante. 
referenciaram sobre os conceitos aqui postos, mas possuíam uma espécie de prerrogativa em comum: a busca por possíveis saídas para fugirmos de ações que ocorrem pautadas apenas em pré-determinações.

A questão da tecnologia fora trabalhada amplamente por Flusser (2002) ao colocar a necessidade de superarmos a programação para podermos nos comunicar verdadeiramente. Ao atribuir tal tarefa à filosofia da fotografia, colocando-a como único caminho possível à liberdade, tal pensador aponta para a urgência de refletirmos sobre a possibilidade de produzirmos, de fato, o novo. Para ele, "o problema central da sociedade telemática utópica é o da produção de informações novas" (FLUSSER, 2008, p. 123). Mas, se estar programado é característica fundante desses aparelhos, como contrariar as suas delimitações e produzir informações novas por meio deles? É nessa busca que o autor aponta um viés de saída para tal limitação.

Nesse sentido, para a formulação de tal resposta, propomos primeiramente uma reflexão que nos leva à conceituação daquilo que Michel Foucault, analisado por Giorgio Agamben (2009)10, apresenta como dispositivo. Extrapolando as conotações do senso comum para tal termo (que o equivaleriam apenas à materialidade do aparelho), a definição foucaultiana-agambeana (AGAMBEN, 2009, p. 35) o apresenta como "[...] conjunto de práticas e mecanismos (ao mesmo tempo linguísticos e não-linguísticos, jurídicos, técnicos e militares)" que carregam estratégias de fazeres e de pensamentos as quais não possuem nenhum fundamento no "ser", ou em qualquer ideia ontológica. O dispositivo é uma dinâmica, um conjunto "de saberes, de medidas, de instituições" (ibid.) que remete a processos de subjetivação, ou seja, de produção de sujeitos. Para os autores, a linguagem é o mais antigo dos dispositivos.

Desse modo, estamos todos os seres viventes atravessados por vários dispositivos: práticas, tecnologias, discursos e regras, por meio das quais se movimentam as relações de poder ou a rede que as interliga.

Generalizando posteriormente aja amplíssima classe dos dispositivos foucaultianos, chamarei literalmente de dispositivo qualquer coisa que tenha de algum modo a capacidade de capturar, orientar, determinar, interceptar, modelar, controlar e assegurar os gestos, as condutas, as opiniões e os discursos dos seres viventes (AGAMBEN, 2009, p. 13). 
Sendo assim, observando tais abordagens, podemos compreender não só o aparelho, mas principalmente a programação flusseriana enquanto dispositivo, ou seja, enquanto mecanismo que produz subjetividades intencionadas. Desse modo, o sujeito, ao ser orientado por tais dispositivos, acaba subjugado às características teleológicas que Deleuze e Guattari (1996) citavam ao introduzir as discussões sobre a compreensão de um Corpo sem Órgãos (CsO).

Sobre teleologia, nos referimos, a partir da perspectiva apontada por tais autores, à compreensão de que cada parte (órgão) que pertencente a um todo (corpo) estaria designada a desempenhar determinada função específica, tal qual os pulmões são designados à respiração, constituindo um organismo. Contudo, inspirados no que afirma Antonin Artaud no seu Para acabar com o juízo de Deus ${ }^{11}$, bem analisado por Deleuze e Guattari (1996), nos perguntamos: para desprogramarmos os organismos, seria necessário, então, declarar guerra aos órgãos?

Assim, além de propormos a compreensão flusseriana de programação associada ao conceito foucaultiano de dispositivo, a associamos também ao que estes últimos filósofos definem como organismo teleológico. Ao fazermos uma analogia, um órgão, no sentido teleológico de Deleuze e Guattari (1996), seria aquilo que Flusser (2002) viria a pontuar como instrumento ${ }^{12}$. Em termos de aparelho fotográfico (filosofia da fotografia), e expandindo-o para aplicação contemporânea também em aplicativos e plataformas digitais, poderíamos dizer que seus órgãos seriam, por exemplo, as ferramentas e partes que os compõem e que possuem funcionalidades pré-determinadas, compondo o todo intencional do que chamamos de aparelho programado, um organismo. Logo no início de Filosofia da caixa-preta (2002), Flusser pontua que o aparelho foi feito para produzir ações que já foram previstas por quem os projetou. Não seria esta, então, uma espécie de teleologia das ferramentas que compõem esses aparatos, contra a qual devemos trabalhar?

O enfrentamento questionado por Artaud e desenvolvido por Deleuze e Guattari (1996) não seria em relação aos órgãos propriamente ditos, aos instrumentos, ou mesmo aos aparelhos que nos servem aos funcionários simulando, reproduzindo e projetando um tipo de pensamento, mas, sim, à constituição de teleologias que desaguam na constituição de organismos: a programação. A construção desses é composta por uma certa organização prevista de suas partes estruturantes, ele é um dispositivo que funciona para orientar uma certa conduta programada do corpo. Ao constituí-lo, estamos lidando com a implementação

${ }^{11}$ Poema escrito em 1947 para ser proferido em uma transmissão radiofônica francesa, na qual foi censurado.

12 “Simulação de um órgão do corpo humano que serve ao trabalho" (FLUSSER, 2002, p.18). 
de um sistema pré-determinado composto pelas relações estabelecidas entre seus constituintes, as quais direcionam de forma restritiva o modo como devemos brincar com essas ferramentas. 0 aparelho-programado seria o corpo-organismo.

Assim, percebemos que a grande problemática flusseriana a respeito da imposição de programas é a de estarmos sujeitos apenas à limitação das ações daquilo que Flusser colocava como "[...] jogo de combinação com elementos claros e distintos" (2002, p. 18). Nesse sentido, se voltarmos à contextualização do cenário midiático digital, por mais que esse se apresente enquanto agente facilitador do cotidiano, acaba também por restringir nossas ações às interfaces e às possibilidades pré-programadas inscritas nos aparelhos.

Como poderíamos, então, reconfigurar programações, destituindo assim a imposição de certos organismos, reativando o corpo e ressignificando os órgãos do aparelho? Um indício para respondermos a esse questionamento pode ser a subversão dos padrões que regem os modos de ação que cada aparelho deve ter. E, então, voltamos a Deleuze e Guattari e perguntemos: "Por que não caminhar com a cabeça, cantar com o sinus, ver com a pele, respirar com o ventre?" (1996, p. 10). O problema gira em torno do dispositivo que atravessa os programas, da imposição de certos padrões de uso, da sedimentação de formas e organizações dominantes e hierarquizadas.

Deleuze e Guattari (1996) concluem que a guerra é, na verdade, declarada ao corpo ordenado, ao organismo, e não aos órgãos ou ao corpo enquanto potência. A compreensão da necessidade, então, da fabricação do $\mathrm{CsO}$, sobre a qual nos debruçaremos mais à frente, está relacionada a estarmos em estado de abertura às intensidades, buscando subjugar as programações, condicionando-as aos movimentos de energia pulsante que pairam sobre os processos criativos dos funcionários.

Flusser pontua que uma maioria crescente da sociedade age utilizando as teclas previsíveis de aparelhos: “Destarte vai surgindo uma maré de programas (de softwares) que não mais articulam intenções, desejos, decisões humanas, mas agora somente programas pré-estabelecidos" (2008, p. 105). Esse fenômeno é a entropia, que ocorre quando não surgem alimentações de fora do circuito, como se não houvesse ninguém por trás das imagens criadas, dos conteúdos produzidos, nenhuma intenção, além de uma repetição cíclica de padrões e de usos.

O autor vai, então, como vimos, denominar os fotógrafos como os representantes dos imaginadores, esses funcionários que escapam. O que nos parece aqui é que devemos manter o esforço de transformar funcionários em fotógrafos, mesmo que esses não estejam necessariamente introduzindo apenas informações novas. 0 objetivo de Flusser é nos fazer 
sair de uma teleologia e ir em busca da desprogramação de dispositivos padronizantes, criando os possíveis contradispositivos, produzindo $\mathrm{CsO}$, na proposta de trazer o que ele chama de caixa preta para a superfície, como abordaremos mais adiante. 0 que vale é a intenção de criador ao apertar as teclas, é conseguir promover informação nova dentro de um sistema em que isso mesmo se torna improvável.

\section{Para brincar com caixas pretas: fabricando contradispositivos sem órgãos}

Flusser (2002) nos alerta que, apenas se conseguirmos penetrar e abrir as caixas pretas dos aparelhos e utilizá-las a nosso proveito, dialogando, continuaremos pensantes e usaremos aparelhos que sirvam para as nossas reais necessidades. Segundo ele (2002, p. 54), quanto mais naturais e automáticos pareçam os usos e os resultados alcançáveis (e desejáveis) dos aparelhos, mais perigosos, mais caixa preta. 0 filósofo sugere, então, que tragamos os programas para a superfície, que abramos a caixa e brinquemos com ela, pois utilizar os aparelhos reiteradamente do modo como comumente já vêm sendo utilizados potencializará apenas uma replicação de funcionalidades já conhecidas, uma padronização. Entropia, fim da informação.

Ao pensar a definição de aparelho, resgatando o seu significado etimológico, Flusser (2008, p. 20) retoma a origem do termo em latim, pontuando que a sua derivação vem dos verbos adparare e praeparare, o que respectivamente significam prontidão para algo e disponibilidade em prol de algo. Mas como seriam essas disponibilidades configuradas a fim de transpassar as organizações entrópicas? Para o autor, os aparelhos produtores de imagem foram inventados "[...] não apenas a fim de tornarem visíveis virtualidades, mas igualmente para computarem tais virtualidades em situações pouco prováveis" (2008, p. 31). A partir desse viés de análise, experiências empíricas se destacariam não por serem impossíveis na virtualidade dessa plataforma, mas justamente por explorarem recursos nem sempre esperados como perspectivas de uso. Há um rompimento da teleologia.

Assim como pontuava Walter Benjamin (1994), que o método é desvio, devemos traçar caminhos, por vezes indiretos, que permitam também o surgimento daquilo que o autor alemão denominava como "centelhas do acaso". A improbabilidade colocada por Flusser refere-se muito mais a menores incidências do que a ineditismos. É preciso deliberadamente utilizar de intenções inovadoras para manejar o programa e lutar contra a sua automaticidade (FLUSSER, 2008, p. 34). E, muitas vezes, essas intenções exigem a 
ampliação do próprio limite do programa para que sejam de fato inovadoras. É a partir dessas possibilidades pouco prováveis, que passam a ser utilizadas pelos fotógrafos, que um novo panorama vai sendo configurado e as relações antes vigentes vão sendo alteradas.

Retomemos os diálogos filosóficos que iniciamos no tópico anterior: de acordo com Deleuze e Guattari, também é a restituição da verdadeira liberdade que a fabricação de um CsO propicia. É possível que, ao longo do processo, o corpo se perca, se destrua, se esvazie, mas, na verdade, ele é um mecanismo de plenitude, “[...] o CsO é também pleno de alegria, de êxtase, de dança", dizem os autores (DELEUZE; GUATARRI, 1996, p. 11).

A constituição de um $\mathrm{CsO}$ enquanto conjunto de (contra)práticas ativas a sua capacidade de manter-se em devir, de reenergizar as dinâmicas e as relações de poder. 0 papel do sujeito que brinca com as possibilidades que lhes são dadas é ser o agente que caminha entre as frestas, procurando os espaços vazios ou ainda não explorados. Nesse constante brincar, devemos buscar as situações com potência criativa ou expansiva, dentro do espectro oferecido. 0 brincar ${ }^{13}$, para Flusser, é a chave da questão dos imaginadores.

Mesmo que ações de funcionamento e consumo se tornem hábitos, padrões de comportamento, é necessário investir na relação dialógica entre funcionários e programas e perceber como novos conteúdos podem ser concebidos a partir dessas possibilidades que surgem, ao mesmo tempo em que as próprias possibilidades são constantemente reprogramadas para poder propiciar novas experiências no seu menu.

A dinâmica entre o estabelecimento de um organismo e a fabricação de um CsO é constante. Segundo Deleuze e Guattari (1996), o CsO é algo que nunca se dá por encerrado: é o verdadeiro exercício simultâneo de desconstrução-construção, de desterritorializaçãoreterritorialização - percebendo que esses duplos não funcionam como polaridades, mas como um mesmo movimento.

Os autores dizem que o CsO é como um ovo, aquela fase anterior ao organismo, desprovida de órgãos organizados, mas que contém em sua potência uma quantidade de energia gerativa enorme. "Ele só pode ser ocupado, povoado por intensidades. Somente as intensidades passam e circulam" (DELEUZE; GUATTARI, 1996, p. 12). É vida, energia em ebulição, em movimento constante. Desfazer o organismo não é matá-lo, mas abri-lo às possíveis conexões que o atravessam. Fabricar CsO é conduzir quebras de obviedade, construir contradispositivos. No sentido de Agamben (2005, p. 14), faz-se necessário

13 “O nosso desafio não é uma sociedade de deuses ou de artistas inspirados, mas sim uma sociedade de jogadores” (FLUSSER, 2008, p.91). 
profanar os dispositivos, restituir ao livre uso dos homens. 0 contradispositivo subverte a ordem esperada das coisas.

Vimos que o dispositivo é um vínculo que compreende e atrela as relações de poder; as resistências, por sua vez, podem funcionar como contradispositivos na medida em que, por meio de um movimento comum, não cessam de inverter, recusar, reorganizar e perverter o seu funcionamento (ALVIM, 2012, p. 82).

Para estabelecermos movimentos subversivos, contradispositivos que busquem quebrar a programação, é preciso reconhecer os dispositivos, os padrões que os compõem. Todavia, os aparelhos fotográficos enquanto caixas-pretas são demasiadamente difíceis de serem penetrados, pois segundo Flusser (2002, p. 16), ao vermos seus inputs e outputs não estamos diante dos processos codificadores pertencentes ao seu interior. Por isso, o objetivo para irmos rumo à liberdade prometida pela filosofia da fotografia seria brincar com essa caixa: irmos em busca do uso criativo do aparelho, desprogramando-o, incitando-o a novas configurações, estabelecendo contradispositivos, fabricando CsO. E como fazê-lo?

Seria necessário, de acordo com Deleuze e Guattari (1996, p. 22):

[...] instalar-se sobre um estrato, experimentar as oportunidades que ele nos oferece, buscar aí um lugar favorável, eventuais movimentos de desterritorialização, linhas de fuga possíveis, vivenciá-las, assegurar aqui e ali conjunções de fluxos, experimentar segmento por segmento dos contínuos de intensidades, ter sempre um pequeno pedaço de uma nova terra. É seguindo uma relação meticulosa com os estratos que se consegue liberar as linhas de fuga, fazer passar e fugir os fluxos conjugados, desprender intensidades contínuas para um CsO.

É preciso, contudo, atentar para o fato de que buscar quebras de probabilidade, ainda no sentido da fabricação de um CsO, pede, segundo os autores (DELEUZE; GUATTARI, 1996, p. 23), prudência, como regra inerente à experimentação. Por conseguinte, ao invés de buscarmos a destruição completa dos organismos, teríamos de traçar um plano em relação ao seu melhor uso, sua reinvenção.

No mesmo sentido, Flusser sugere que a ideia que desprograma o programa não deve vir de um fotógrafo-deus, mas de um fotógrafo-jogador:

O "artista" brinca com o propósito de produzir informação nova. Ele delibera. [...] 0 método a que recorre nesse jogo não é o de uma "inspiração" qualquer (divina ou anti-divina), mas sim o do diálogo com os outros e consigo mesmo: um diálogo que lhe permita elaborar informação 
nova junto com informações recebidas ou com informações já armazenadas (FLUSSER, 2008, p. 126).

A questão do contradispositivo, do $\mathrm{CsO}$ e da desprogramação está justamente na compreensão do deliberar, na liberdade, que é entrar no jogo e brincar com a caixa preta: "De homo faber passaríamos a homo ludens", diz Flusser (2008, p. 130).

\section{Para brincar com imagens técnicas}

Por diferentes vezes até aqui, trouxemos que um dos desafios da nossa sociedade atual, a partir de uma interpretação flusseriana, seria perceber como o nosso ato de brincar pode funcionar como um contradispositivo, mesmo que não precisemos mergulhar tão fundo na caixa preta. É também no jogo da superficialidade que expandimos a comunicação. Para Flusser, "os aparelhos não são refletores, mas projetores. Não 'explicam' o mundo, como o fazem as imagens tradicionais, mas 'informam' o mundo" (FLUSSER, 2008, p. 71). Assim, os conteúdos midiáticos que produzimos por meio dos aparelhos podem ser informativos ou redundantes, dependendo da intenção de desafiá-los ou não.

Novas tecnologias, novas plataformas, novos suportes, novos hardware e software virão e tornarão as estereotipias de agora ultrapassadas por outras que virão e logo deixarão de ser novas. Vem sendo assim ao longo da história da comunicação. A consciência é entender que os jogos se servem como diálogos mais do que como discursos (FLUSSER, 2008, p. 95).

0 programa não necessariamente vai escravizar os funcionários, porque é aberto a modificações, e, mesmo que visem a programar o comportamento da sociedade e tentem automatizá-la, se pensarmos que ele também pode ser programado conforme as intenções da sociedade, começamos a perceber onde habita o jogo. Nenhum aparelho é autônomo ao ponto de não precisar de que alguém o comande e aperte suas teclas, ainda que a única possibilidade seja um comando mínimo (como ligar e desligar ou clicar em um preset ${ }^{14}$ ). Mesmo assim, Flusser nos ensina a utilizá-lo em função de nossas ideias.

Por mais que saibamos que programas, enquanto dispositivos, possam ser extremamente fechados à intencionalidade de usos improváveis, tendo em vista muitas das teleologias delineadas por seus programadores e de suas características limitantes enquanto organismo proposto, ainda assim há espaço para brincarmos com as caixas-pretas

14 Termo referente a configurações pré-determinadas, normalmente acessíveis a um clique. 
que as compõem. Por mais que saibamos que todas as virtualidades relacionadas à produção de imagens encontrem-se já reunidas, assim como aponta Flusser, devemos seguir caminhando por meio de seus direcionamentos, os quais nos levam à busca por combinações não óbvias dos fios disponíveis ${ }^{15}$, da troca de informações disponibilizadas para que assim possam surgir expansões em informações novas. Sabemos que desmontar o programa é intenção incrustada de utopia, porém brincar com programas e desconfigurar previsibilidades intencionais de ferramentas, por exemplo, nos encaminha a não-teleologias, a contradispositivos, à fabricação de $\mathrm{CsO}$. $\mathrm{O}$ jogar pode indicar outros pontos de costura.

O smartphone, por exemplo, é um dos principais aparatos tecnológicos utilizados atualmente. Por meio de seus sistemas operacionais e suas possibilidades de aplicativos, existem inúmeras possibilidades de usos. Por mais que cada uma delas tenha limites para os esgotamentos de tais fins, o usuário contribuirá para a construção de sentido destas funcionalidades, podendo expandir ou mesmo contrapor a intencionalidade inicial programada. Isso pode funcionar como uma espécie de quebra de obviedade desses aparelhos, um rompimento de suas teleologias iniciais e do organismo existente.

O celular "inteligente", por exemplo, começou a ser idealizado em meados da década de 1990 e tinha como objetivo disponibilizar possibilidades de realização de atividades que iriam além do propósito inicial dos telefones móveis, o de facilitar a comunicação ponto a ponto. Anos depois, inúmeras alternativas ampliam os propósitos, transformando nosso modo de nos comunicar, permeado hoje por aplicativos tais como o WhatsApp, que reconduzem a forma como entramos em contato com alguém via dispositivo de comunicação móvel.

Por mais que o surgimento de novas possibilidades siga seu fluxo na história das comunicações, por modificações em sua grande maioria propostas pelos próprios programadores, é importante nos atermos ao fato de que muitas das transformações tecnológicas surgem a partir de como os funcionários se relacionam com tais aparelhos, várias vezes por meio de usos criativos e subversivos, expandidos para além das expectativas iniciais dos próprios criadores-programadores.

Caso não estivéssemos continuamente jogando e buscando entender quais os limites dos aparelhos, e como poderíamos de certa forma transpassá-los, poderíamos estar ainda com versões atualizadas bem menos potentes dos primeiros celulares e aplicativos, por

15 “O seu instrumento não será a pá que escava, mas sim o tear que combina os fios” (FLUSSER, 2008, p. 98). 
exemplo. A ação dos imaginadores ampliou as potências das tecnologias inteligentes, dos aparelhos e dos programas que os atravessam.

De acordo com Piza (2012), a rede social digital Instagram foi criada na intenção inicial de resgatar a nostalgia do instantâneo fomentada por câmeras Polaroids ${ }^{16} .0$ mote do programa era: "tire uma foto e depois escolha um filtro para transformar sua aparência em uma memória a ser guardada para sempre"17. Havia na época oito filtros ${ }^{18}$ disponíveis, que simulavam efeitos visuais de filmes fotográficos analógicos para serem aplicados às imagens digitais e postados na rede. Em uma década de existência, quantas funcionalidades surgiram que extrapolaram esse intuito inicial?

Voltado para a edição e o compartilhamento de imagens, por meio de uma rede em que outros usuários podem comentar, curtir ou compartilhar tais publicações, no início, o software operava apenas com fotografias fixas, mas desde 2013 vídeos (na época, de até 15 segundos; e hoje comportando até 60 minutos) e os chamados boomerangs também foram acoplados às possibilidades. Com esta última ferramenta seria possível realizar gifs animados por meio da captação de mini-vídeos que são colocados em repetição contínua (de frente para trás e de trás para frente, em looping), para serem postados pelos usuários.

Expandindo o uso inicialmente proposto pelo programa, o grupo musical brasileiro Pato Fu apropriou-se da ferramenta para produzir o videoclipe Private Idaho ${ }^{19}$, em 2018. Ao invés de sequências tradicionais de vídeo, comuns à narrativa deste gênero audiovisual, sendo também o videoclipe um espaço de experimentação, o produto foi realizado a partir de cerca de setenta boomerangs, produzidos durante o show de estreia da turnê do álbum Música de Brinquedo 2, lançado em 2017. 0 produto audiovisual mescla a letra da música e as imagens do show, resultando em um lyric video 20 .

A iniciativa apropriou-se parcialmente da ferramenta disponibilizada pelo Instagram, a utilizando inicialmente de acordo com a sua programação prevista, ou seja, a princípio, a partir de sua teleologia, captando vídeos curtos independentes que são reproduzidos de forma contínua em vai-e-vem entre o seu início e seu fim, possuindo uma duração média entre cinco e seis segundos cada. Entretanto, em seguida, a banda mineira brincou com a ferramenta, desmontando o objetivo central de seu organismo, para fazer um

\footnotetext{
${ }^{16}$ Câmera analógica inventada por Edwin Land em 1948, a qual permite que o processo de revelação de uma imagem fosse instantâneo, pois ao produzir uma fotografia a câmera ejetava o fotograma impresso produzido.

17 Disponível em: <https://www.mlabs.com.br/blog/instagram/> Acesso em: 20 de Maio de 2020.

${ }_{18}$ Máscaras de tratamento de imagens que funcionam como presets.

${ }^{19}$ Disponível em: <https://www.youtube.com/watch?v=grQuf-Jfv7c> Acesso em: 30 de Novembro de 2019.

20 Expressão da língua inglesa comumente utilizada para fazer referência a um produto audiovisual cuja formatação básica consiste em apresentar uma música através do conjunto entre o áudio de referência e uma composição visual a qual tem como protagonista a letra da faixa em questão.
} 
videoclipe com mais de três minutos de duração, ou seja, uma criação que vai além da obviedade imediata prevista pelo programa e que, inclusive, usa de outras plataformas de difusão. Mesmo que esse uso já estivesse contido, de algum modo, no panorama das suas possibilidades, a ferramenta Boomerang não foi criada com o intuito de ser mecanismo voltado para a realização de videoclipes.

Até aqui nos atemos prioritariamente a observar o Instagram. Todavia, esses exemplos acontecem de modo similar em outras plataformas. Os programas estão imersos nessa constante fluidez de reprogramações de suas configurações iniciais. 0 Youtube, por exemplo, surgiu como um espaço de compartilhamento de vídeos caseiros, e, ao postar $M e$ at the Zoo 21 , vídeo que mostra por menos de vinte segundos um homem na frente de uma jaula de zoológico, Jawed Karim, um dos fundadores da plataforma, provavelmente não imaginava todas as ferramentas e usos posteriores que seriam inseridos nela. Tampouco que o caráter amador das primeiras imagens compartilhadas iria desdobrar-se em inúmeras vertentes de criações em diferentes campos de produção de conteúdo, inclusive profissionalmente, que coabitam esse ciberespaço e que foram surgindo a partir do esgarçamento desse uso inicial.

O recurso de transmissões ao vivo que configuram as tão recorrentes e populares lives no Instagram foi lançado em 2017. Realizar esse tipo de transmissão já era possível desde 2008 por meio do Youtube. Porém, a partir do cenário mundial de distanciamento social provocado pela pandemia de Covid-1922, esse recurso popularizou-se para além da partilha do cotidiano dos usuários comuns da rede, passando a ser utilizado como ferramenta de entretenimento (shows musicais, entre outros), educação (aulas online) e debate (chats e entrevistas), transmitidos pela plataforma e, em 2020, hiper difundidos no Brasil.

Nessa zona de constante adequação decorrente dos jogos que transpõem aquilo que já é minimamente pré-determinado, funcionários e programas são modificados, em um movimento de remodelagem, de desconstrução do organismo fixo, um jogo de brincar com a caixa preta. Mesmo tendo consciência dessas pré-determinações, compreendendo que existem programações e dispositivos poderosos, que compõem organismos estruturados e incidem sobre os aparelhos, seguiremos flusserianamente acreditando que há sempre a possibilidade de brincarmos com tais barreiras, ressignificando-as. Tudo é uma questão de estratégia de programação e desprogramação. A nossa liberdade está em ir contra essas pré-

21 Disponível em: <https://www.youtube.com/watch?v=jNQXAC9IVRw> Acesso em: 07 de Novembro de 2019.

${ }^{22} \mathrm{Na}$ quarentena, o mundo virou uma live. Disponível em: <https://exame.com/revista-exame/o-mundo-e-uma-live/>. Acesso em 29 de Maio de 2020 
determinações, em hackeá-las ${ }^{23}$ da forma mais simples que é reinventando seus usos, criando contradispositivos de superfície, fabricando $\mathrm{CsO}$ e adicionando novas informações para evitar a entropia. Isso só é possível através da abertura, do diálogo e do jogo dos imaginadores.

\section{Desprogramando dispositivos midiáticos}

Em uma de suas passagens reflexivas acerca dos questionamentos da filosofia da fotografia, Flusser (2008, p. 32) colocou que se chimpanzés tivessem acesso ao teclado de sua máquina, acabariam por produzir o mesmo texto que seria por ele escrito, mesmo que para isso demorassem bilhões de anos. Desse modo, poderíamos dizer que escrever um texto legível e complexo seria ação previamente inscrita dentro das programações possíveis de um aparelho de escrita. Porém, sabemos que, caso tal primata soubesse minimamente as possibilidades de combinação de teclas mais prováveis que reproduziriam o referido texto (e houvesse intenção para tanto), o tempo utilizado para sua concepção provavelmente seria bem menor.

A partir dessa reflexão, a experiência com o animal pode nos revelar que o esgotamento das possibilidades inscritas em um programa pode levar tempo indeterminado caso não saibamos minimamente como manipular suas funcionalidades. Ela também nos revela que, considerando a complexidade da produção de um longo e inédito texto escrito, nem sempre os programadores sabem ou controlam onde podem desaguar suas programações. Por mais que já saibamos das pré-determinações dos programas, ainda assim, podemos agir enquanto imaginadores, fazendo com que os aparelhos trilhem os caminhos pretendidos por nós, aqueles que imaginamos, e acreditando que, com intenção e domínio de linguagem, não precisaríamos de bilhões de anos para reproduzir o mesmo texto realizado por Flusser.

Em meio às céleres mudanças que ocorrem ao nosso redor, percebemos o protagonismo midiático cada vez mais evidenciado no contexto contemporâneo. Muniz Sodré (2001) ao fazer referência à obra Ética a Nicômaco ${ }^{24}$ de Aristóteles (escrita no séc. IV a.C), já nos alertava sobre a formação de um novo ethos ${ }^{25}$. Por meio dele, as relações em

\footnotetext{
${ }^{23}$ Nesse sentido, o verbo "hackear" deve ser entendido como "reconfigurar", explorar novas características, ir além do que os protocolos delimitaram, buscar a superação do controle (SILVEIRA, 2010, p.38).

${ }^{24}$ ARISTÓTELES (384-322 a.C.) Ética a Nicômaco: Aristóteles. São Paulo: EDIPRO, 2014. Apud Sodré (2001).

25 "Consciência atuante e objetiva de um grupo social, [...] instância de regulação das identidades individuais e coletivas" (SODRÉ, 2002, p. 45).
} 
sociedade seriam construídas a partir das relações tecnomediadas entre os indivíduos, transitando por aparelhos multi-telas que reconfiguram a nossa relação com produtos midiáticos. No contexto atual em que estamos inseridos, pensarmos na relação com quaisquer dispositivos sem que esta esteja associada ao protagonismo das imagens técnicas mediadas por aparatos tecnológicos torna-se tarefa difícil.

De acordo com Flusser (2008, p. 84), em meio a um cenário de diminuição do nível intelectual, oral e estético da sociedade, o totalitarismo dos aparelhos será reforçado. Estamos imersos em smartphones e desktops, por meio dos quais se centram nossos modos de consumo e produção comunicacionais contemporâneos. 0 entretenimento, as formas de relacionamento e até mesmo eleições presidenciais andam cada vez mais programadas pelos organismos de aplicativos e plataformas que são manipuladas na ponta dos dedos dos digitadores, os quais assumem, no sentido flusseriano, o papel de portadores de informação. Replicadores ou informadores?

Os objetos culturais (FLUSSER, 2008, p. 51), ou seja, filmes, programas de televisão e de computadores, entre outros, constroem narrativas de poder por meio dos seus dispositivos, feitas para serem reproduzidas. É preciso então, para brincar com a caixa preta das imagens técnicas, colocar-se alerta: "Não é analisando a casa mostrada na fotografia, mas analisando a câmera fotográfica e a intenção do fotógrafo que a decifraremos" (FLUSSER, 2008, p. 55).

Desse modo, tendo como recorte essa configuração contemporânea da idolatria ${ }^{26}$ interligada ao protagonismo das imagens técnicas, como seria possível brincar com os aparelhos e subverter as suas programações, constituindo certo grau de liberdade nesse recorte? Como poderíamos compreendê-los para vislumbrarmos possíveis modelos futuros? Em o Elogio da Superficialidade (2008), Flusser afirma que anteriormente nos era exigido que aprendêssemos a ler, escrever e a elaborar, e que a situação cultural emergente, na qual a aprendizagem é eliminada, se contenta com a programação dos seus participantes. Um possível caminho de fuga, de quebra do programa e produção de contradispositivos, seria provocarmos descontentamentos.

Buscar continuamente as bordas dos programas e reconhecê-las, para poder transbordá-las, torna-se tarefa pujante. Uma das constantes que também se faz necessária é a transformação do modo como devemos olhar para as fronteiras que circundam os processos midiáticos e os campos em que estão inseridos. Assim, considerando uma 
teleologia da mídia, ao invés disso seria mais adequado, então, pensarmos não mais apenas em cinema, televisão ou, como na maioria dos nossos casos abordados, em internet e suas redes sociais. Do mesmo modo, videoclipes, vídeos para as redes sociais, séries televisivas bebem livremente nas mais diversas fontes e alternam-se, não necessariamente encaixandose em apenas uma dessas formas, mas sendo livres para explorar os seus devires, para constituir Corpo sem Órgãos. Persistir no condicionamento desse olhar refere-se à capacidade de manter dispositivos enquanto potencialidades de criação ainda desconhecidas.

Devemos buscar constantemente concepções de usos sociais ${ }^{27}$ das tecnologias de modo que subvertam pré-determinações aos propósitos de seus funcionários e que entendam que o estar programado vai além da sua integração com aplicativos e aparatos tecnológicos. Ao quebrarmos a programação, no sentido de sua previsibilidade, estamos em busca da construção de mediações para além das obrigatoriamente vigentes e de relações que nos conduzam à liberdade almejada por Flusser. Perceber como conteúdos passam a ser concebidos a partir das possibilidades que surgem, ao mesmo tempo em que programas modificam a suas programações iniciais, as absorvendo e propiciando novas possibilidades, surge como maneira de compreendermos como é possível tornarmo-nos além de meros apertadores de botões.

Assim como não chegamos nunca à constituição total de um CsO, pois, segundo Deleuze e Guattari (1996), ele é um limite, ao nos debruçarmos sobre os escritos de Flusser (2002; 2008), temos consciência de que ansiar por uma total quebra de programação é deveras ilusório. Contudo, podemos buscar pelo máximo de esgotamento das possibilidades, alimentando uma tendência ao surgimento dinâmico de novas alternativas, ao desenvolvimento do não imediatamente usual, utilizando assim aparatos em função do anseio dos funcionários imaginadores e não apenas dos programadores de dispositivos. Por isso, é essencial que busquemos nos preparar para decifrar e jogar com (e contra) cada um desses aparelhos, para que, por meio dessa ótica, possamos perceber como eles estão realmente sendo utilizados.

A verdadeira interatividade só existe quando há o diálogo, quando podemos interferir conscientemente no programa e trabalhar junto a ele. Não quando somos levados pelo seu automatismo, muitas vezes autoritário, guiados por interfaces limitadoras, que impedem a alteração de percursos pré-programados, óbvios e padronizantes. Devemos, no

27 "É porque a sociedade decide acionar tecnologias em um sentido interacional que estas se desenvolvem - na engenharia e na conformação social” (BRAGA, 2012, p. 36). 
sentido de Agamben (2009, p. 75), profanar os dispositivos, buscando novos usos, novas formas de brincar.

Nesse sentido, a preparação é o pré-requisito para que aconteçam os acasos pouco prováveis. É o que encaminha o criador na direção dos eventos artísticos, informativos, inesperados. "Em outros termos: quanto maior a soma das informações recebidas, tanto maior a probabilidade de se receberem acasos pouco prováveis" (FLUSSER, 2008, p. 160). É preciso ganhar intimidade, se preparar, para poder agir criativamente. Entretanto, assim como nos alertava Flusser (2008, p. 65), é preciso que direcionemos o nosso olhar constante para os "estalos de gelo", que podem nos sinalizar os futuros locais de rompimento.

Ao falar metaforicamente sobre os tempos atuais, Flusser (2008), por meio de analogias, os compara a um colar que, ao ter seus fios condutores desintegrados, tem suas pedrinhas soltas e amontoadas em composições caóticas. 0 intuito aqui proposto não é de sermos a mão que cata esses compostos e os reorganiza de determinado modo que uma composição final seja entregue ao término dessa leitura. Contudo, tentamos compreender quais são as características desse fio, bem como as possibilidades de encaixe dessas contas, propiciando a possibilidade de que cada interpretante desse texto possa fazer seu próprio colar. Desejamos, ao fim, propiciar possíveis saltos rumo a novos níveis de entendimento, assim como já ansiava Vilém Flusser, mas sempre em busca da liberdade, mesmo ainda que sejamos seres tomados de vertigem ${ }^{28}$.

\section{Referências}

ALVIM, Davis Moreira. 0 que é um contradispositivo? In: Cardernos de Subjetividade. São Paulo: Núcleo de Estudos e Pesquisas da Subjetividade, 2012. p. 120-127.

AGAMBEN, Giorgio. 0 que é um dispositivo? Outra Travessia, Florianópolis, n. 5, p. 9-16, janeiro, 2005.

AGAMBEN, Giorgio. 0 que é contemporâneo? E outros ensaios. Chapecó: Argos, 2009.

BENJAMIN, Walter. Pequena história da fotografia. In: BENJAMIN, Walter. Magia e técnica, arte e política: ensaios sobre literatura e história da cultura. 7. ed. São Paulo: Brasiliense, 1994. p. 91-107.

BRAGA, José Luiz. Circuitos versus campos sociais. In: MATTOS, Maria Ângela; JANOTTI JUNIOR, Jeder; JACKS, Nilda (orgs.). Mediação \& midiatização. Salvador: EDUFBA, 2012, p. 31- 52.

28 "Dei-me conta de que os fios cortados me tinham alimentado, e que estava sendo projetado para a liberdade. Fui tomado pela vertigem da liberdade, a qual se manifesta pela inversão da pergunta "livre de quê" em "livre para fazer o quê". E assim somos todos os migrantes: seres tomados de vertigem” (FLUSSER, 2002, p. 63). 
DELEUZE, Gilles; GUATTARI, Félix. Mil platôs: capitalismo e esquizofrenia. v.3, Rio de Janeiro: Editora 34, 1996.

FLUSSER, Vilém. 0 universo das imagens técnicas: elogio da superficialidade. São Paulo: Annablume, 2008.

FLUSSER, Vilém. Filosofia da caixa preta. São Paulo: Relume Dumará, 2002.

FOUCAULT, Michel. 0 corpo utópico, as heterotopias. São Paulo: N-1 Edições, 2013.

LÉVY, Pierre. Cibercultura. São Paulo: Editora 34, 2010.

PIZA, Mariana Vassalo. O fenômeno Instagram: Considerações sob a perspectiva tecnológica. Monografia (Bacharelado em Ciências Sociais) - Universidade de Brasília. Brasília, 2012.

SILVEIRA, Sérgio Amadeu da. Ciberativismo, cultura hacker e o individualismo colaborativo. Revista USP. São Paulo, n.86, p. 28-39, jun/agos 2010.

SODRÉ, Muniz. Antropológica do espelho: uma teoria da comunicação linear e em rede. Petrópolis: Vozes, 2002.

SODRÉ, Muniz. Sobre a vida anunciada. Galáxia, São Paulo, v.1, n.2, p.113-120, 2001.

\title{
To play with black boxes: deprogramming media devices
}

\begin{abstract}
In the proposed article, we walk through the concepts presented by Vilém Flusser, looking mainly through those who make reference to the freedom of employees in the age of the devices, acting between their loopholes of programation. We try to understand how, in this way, a subversion of the predeterminations of programs with which we relate can be constructed as practice. The idea proposed by the author is that such transgressions are a game of creative and expansive uses of the media, as well as forms of resistance to repetition patterns, which aim at their own interests and configure the programs. We propose a theoretical approximation of Flusser's points of view, in what he called the philosophy of photography, with the concepts of Body without Organs, by Gilles Deleuze and Félix Guattari, and the Foucaultian concepts of device and counterdevice, presented by Giorgio Agamben. According to Flusser, the danger of being dominated by the devices lies in not challenging them and in not understanding their languages. For the philosopher, even chance is registered in the program and, as a consequence, can, at a certain moment, be realized. Although
\end{abstract}


the game is in realizing how we can act based not only on the probabilities predicted by the programs, but also on human intentions that allow us to play in favor of the unlikely possibilities.

\section{Keywords}

Black box. Philosophy of photography. Technical images. Envisioners. Vilém Flusser.

Recebido em 30/05/2020

Aceito em 14/08/2020 